\title{
Prevalence and associated factors of pediatric emergency mortality at Tikur Anbessa specialized tertiary hospital: a 5 year retrospective case review study
}

Gemechu Jofiro $^{1 *}$, Kemal Jemal $^{2} \mathbb{D}$, Lemlem Beza ${ }^{3}$ and Tigist Bacha Heye ${ }^{4}$

\begin{abstract}
Background: Childhood mortality remains high in resource-limited third world countries. Most childhood deaths in hospital often occur within the first $24 \mathrm{~h}$ of admission. Many of these deaths are from preventable causes. This study aims to describe the patterns of mortality in children presenting to the pediatric emergency department.

Methods: This was a five-year chart review of deaths in pediatric patients aged 7 days to 13 years presenting to the Tikur Anbessa Specialized Tertiary Hospital (TASTH) from January 2012 to December 2016. Data were collected using a pretested, structured checklist, and analyzed using the SPSS Version 20. Multivariate analysis by logistic regression was carried out to estimate any measures of association between variables of interest and the primary outcome of death.

Results: The proportion of pediatric emergency department (PED) deaths was 4.1\% (499 patients) out of 12,240 PED presentations. This translates to a mortality rate of 8.2 deaths per 1000 patients per year. The three top causes of deaths were pneumonia, congestive heart failure (CHF) and sepsis. Thirty two percent of the deaths occurred within $24 \mathrm{~h}$ of presentation with $6.5 \%$ of the deaths being neonates and the most common co-morbid illness was malnutrition (41.1\%). Multivariate analysis revealed that shortness of breath $[A O R=2.45,95 \% \mathrm{Cl}(1.22-4.91)]$, late onset of signs and symptoms $[A O R=3.22,95 \% \mathrm{Cl}(1.34-7.73)]$, fever [AOR=3.17, 95\% Cl (1.28-7.86)], and diarrhea [AOR=3.36, 95\% Cl (1.69-6.67)] had significant association with early mortality.

Conclusion: The incidence of pediatric emergency mortality was high in our study. A delay in presentation of more than 48 hours, diarrheal diseases and shortness of breath were significantly associated with early pediatric mortality. Early identification and intervention are required to reduce pediatric emergency mortality.
\end{abstract}

Keywords: Incidence, Pediatrics mortality, Emergency department, Ethiopia

\section{Background}

Child mortality rates remain high globally [1] with around 3.1 million neonates, 2.3 million infants and 2.3 million childhood deaths occurring every year [2]. Mortality rates in children younger than 5 years have dropped from 11.9 million deaths in 1990 to 7.7 million deaths in 2010 [2]. Worldwide, the distribution of deaths in children fewer than five years of age is 33\% in south Asia, 50\% in sub-Saharan Africa, and less than $1 \%$ in high-income

\footnotetext{
* Correspondence: gemechujofiro12@gmail.com

${ }^{1}$ Addis Ababa Regional Health Bureau Department of Emergency, Box 245,

Addis Ababa, PO, Ethiopia

Full list of author information is available at the end of the article
}

countries [3]. Common factors associated with childhood mortality include acute trauma, extremely preterm birth, and late presentation to the emergency units [4]. In resource-poor countries, pneumonia and diarrhea account for $20 \%$ of deaths in children fewer than 5 years old [2]. Malaria, AIDS, acute respiratory-tract infection, measles, and malnutrition were significantly contributed to child mortality [5]. In developing countries 10 to $20 \%$ of severely sick children are admitted to hospital every year [6-8].

In Africa, the childhood mortality rate is 92 per 1000 live births which are 15 times more than that of well-resourced countries [9]. Most childhood deaths 
from preventable communicable diseases and malnutrition were related to poor environmental health, poverty and lack of knowledge [10].

The magnitude and severity of child mortality are exacerbated by different factors, including delays in seeking assessment and treatment, diarrhea, and poor nutritional status [11]. In pediatric departments, early child mortality is commonly caused by preventable and reversible diseases, so urgent treatment and resuscitation are required to avoid poor outcomes [12, 13]. Early identification and treatment of pneumonia, sepsis, malaria, heart failure (secondary to anemia), acute respiratory tract infections, and diarrheal diseases has been shown to reduce childhood mortality in acute pediatric hospitals [14-17]. Effective intervention and good emergency care of children requires effort and coordination starting from the bedside up to the governmental level. Critical clinical issues, such as shortness of breath, fast breathing and fever with seizure are some of the preventable causes contributing to childhood mortality [12]. Despite advances in public health systems in Ethiopia through global partnerships, there is still a lack of well-organized pediatric emergency units. There is also limited information regarding pediatric mortality patterns, causes and associated factors [18].

Mortality rate is a reflection of the severity of illness and the quality of treatment of patients in pediatric emergency departments. The risk factors associated with the mortality of pediatric age groups in developing countries are largely unknown. This study aims to provide baseline pediatric mortality and valuable associated data essential to health care providers and administrators. This will help them allocate resources to the development of interventions, effective prevention and community education programs to reduce preventable childhood deaths in Ethiopia.

\section{Method}

\section{Study design and period}

This is a five-year retrospective chart review of cases presenting to an urban emergency department (ED) between January 1, 2012 and December 30, 2016.

\section{Study area}

Tikur Anbessa Specialized Tertiary Hospital (TASTH) is an eight hundred bed hospital in Addis Ababa, Ethiopia. It services the most critical referred patients throughout the country. The pediatric emergency department had 42 beds and sees approximately 13,300 presentations per year. It was staffed by two pediatric emergency medicine specialists, residents, and 46 nurses.

\section{Inclusion criteria}

Study data include pediatric patients aged 7 days to 13 years who died in the pediatric ED during the study period.

\section{Exclusion criteria}

Pediatric patients aged 7 days to 13 years who died in the intensive care unit (ICU), neonatal care unit (NICU), or pediatric ward were excluded from the dataset. Patients with incomplete documentation were also excluded.

\section{Data collection}

Data were collected by trained professional nurses using a pre-tested data collection form, which was adopted from previous similar studies [19-22]. Data collected includes socio-demographic characteristics, mode of transportation, clinical presenting features, and the main medical cause of mortality.

Age was categorized into four groups: i) neonate (7 to 28 days), ii) infant (one month to one year), iii) pre-school (one year to five years), and iv) school age (five years to thirteen years) [19,20].

Referral sources were categorized into: i) internal health institution, ii) external health institution, and iii) self-referral [22].

Clinical data included nutrition status, episode of diarrhea within last year, previous hospital visit and/or admission within the last year, and type and duration of clinical presenting signs and symptoms. Nutritional status of the study participants was grouped into well-nourished and malnourished (mild, moderate, and severe) [22].

The outcome (pediatric mortality) was classified based on early mortality (death within $24 \mathrm{~h}$ of arrival to the ED) and late death (death more than $24 \mathrm{~h}$ after arrival to the ED) $[19,20]$.

Finally, the causes of mortality were defined according to the health management information system (HMIS) and international disease classification (IDC) at the hospital level across the country with related different pediatric age divisions [21].

Raw data on the causes and associated factors of pediatric emergency mortality were obtained from a secondary data source (HMIS registration books, medical chart or patient folder sheet, clinical care notes, and the hospital death certificate).

\section{Data processing and analysis}

Data were analyzed using Statistical Package for Social Science (SPSS) version 20. Description of means, simple frequencies, proportions, and rates of the given data on each variable was calculated. Binary logistic regression was assessed to determine the relationship and association between dependent and independent variables. Crude odds ratios from bivariate logistic regression and adjusted odds ratios from multivariate logistic regression were calculated for potential confounding factors between the variables. A $p$-value of less than 0.05 was considered statistically significant and adjusted odds ratios 
with 95\% confidence interval $(\mathrm{CI})$ were calculated to determine strength of association.

\section{Ethical consideration}

Ethical clearance and approval were obtained from the Ethical Committee of the Department of Emergency Medicine, College of Health Science, School of Medicine, Addis-Ababa University. Official letter was obtained from the Department of Emergency Medicine to the clinical director of TASTH. The ethical approval was received from the ethical committee for verbal consent from pediatric emergency department and Card Room staff before joining the study. Confidentiality was maintained in each level of the response. In view of the retrospective nature of this study and the secondary use of data from the health management information system database, study participant and family member consent was waived

\section{Results}

Over the five-year study period, a total of 12,240 children ( 7 days old to 13 years old) presented to the pediatric emergency unit; 499 (4.1\%) deaths were recorded. Of these, 338 (67.7\%) pediatric deaths fulfilled the criteria for analysis, while the remaining 161 (32.3\%) records were excluded because of incomplete documentation.

Table 1 lists the frequency distribution of socio-demographic characteristics and clinical presenting features of the study participants. More deaths occurred in males (56.5\%), with a male to female ratio of 1.3:1. The average age was $37.5( \pm$ standard deviation $=43.2)$ months. Nearly half of the participants came from Addis Ababa region with more than $92.6 \%$ referrals from different health institution. Half of the study patients had previously visited a hospital, and more than $90 \%$ patients had a history of a hospital admission with different medical causes. Of all the deaths analyzed for this study, only $17.8 \%$ patients had a history of previous diarrhea within last year, and around $26.9 \%$ had history of malnutrition.
Table 1 Distribution of socio-demographic characteristics and clinical presenting features of study participants in PED at TASTH, Addis Ababa from 2012 to 2016 inclusive

\begin{tabular}{|c|c|c|}
\hline Variables $(n=338)$ & Frequency & Percentage (\%) \\
\hline \multicolumn{3}{|l|}{ Sex } \\
\hline Male & 191 & 56.5 \\
\hline Female & 147 & 43.5 \\
\hline \multicolumn{3}{|l|}{ Age category } \\
\hline Neonate & 69 & 20.4 \\
\hline Infant & 92 & 27.2 \\
\hline Pre-school age & 98 & 29.0 \\
\hline School age & 79 & 23.4 \\
\hline \multicolumn{3}{|l|}{ Respondent residence } \\
\hline From Addis Ababa & 164 & 48.5 \\
\hline Out of Addis Ababa & 174 & 51.5 \\
\hline \multicolumn{3}{|l|}{ Source of referral } \\
\hline $\begin{array}{l}\text { From health institution (internal and } \\
\text { external) }\end{array}$ & 313 & 92.6 \\
\hline Self-referral & 25 & 7.4 \\
\hline \multicolumn{3}{|l|}{ Previous hospital visits within last year } \\
\hline Yes & 165 & 48.8 \\
\hline No & 173 & 51.2 \\
\hline \multicolumn{3}{|l|}{ Previous hospital admission within last year } \\
\hline Yes & 152 & 92.1 \\
\hline No & 186 & 7.9 \\
\hline \multicolumn{3}{|c|}{ Previous episode of diarrhea within last year } \\
\hline Yes & 60 & 17.8 \\
\hline No & 278 & 82.2 \\
\hline \multicolumn{3}{|l|}{ Previous Nutritional status } \\
\hline Normal & 247 & 73.1 \\
\hline Malnourished & 91 & 26.9 \\
\hline \multicolumn{3}{|l|}{ Duration of signs\& symptoms } \\
\hline$\leq 2$ days & 134 & 39.6 .0 \\
\hline$>2$ days & 204 & 60.4 \\
\hline
\end{tabular}

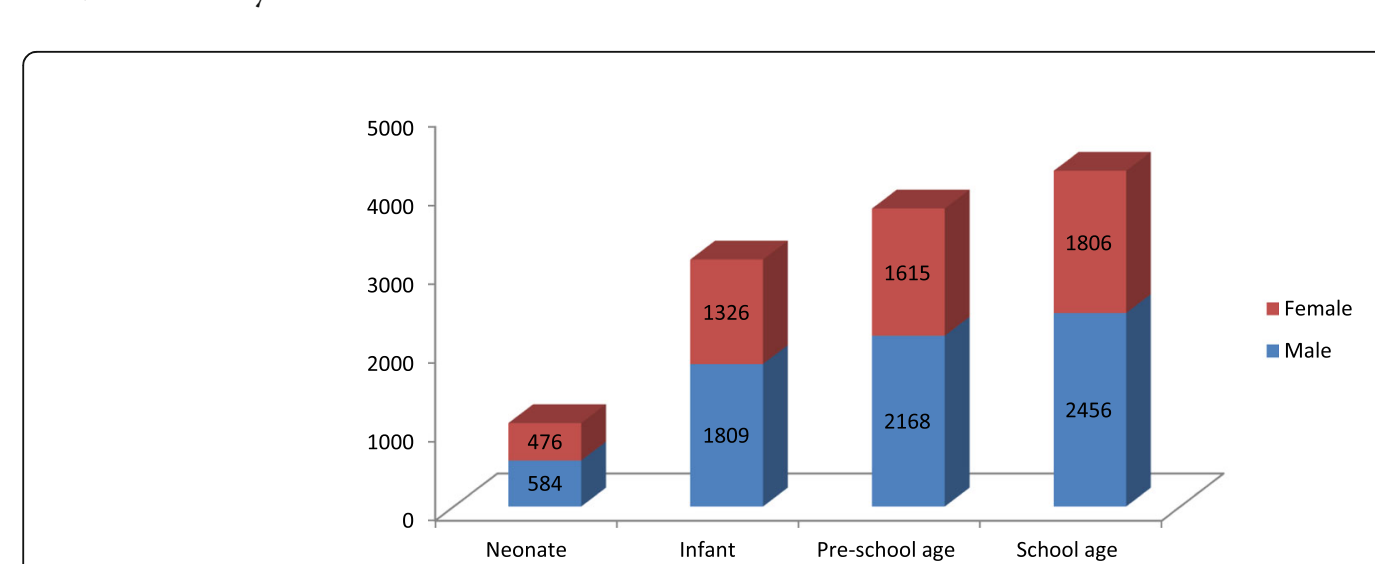

Fig. 1 Sex identification among pediatric age group division in PED at TASTH, Addis Ababa from 2012 to 2016 inclusive 


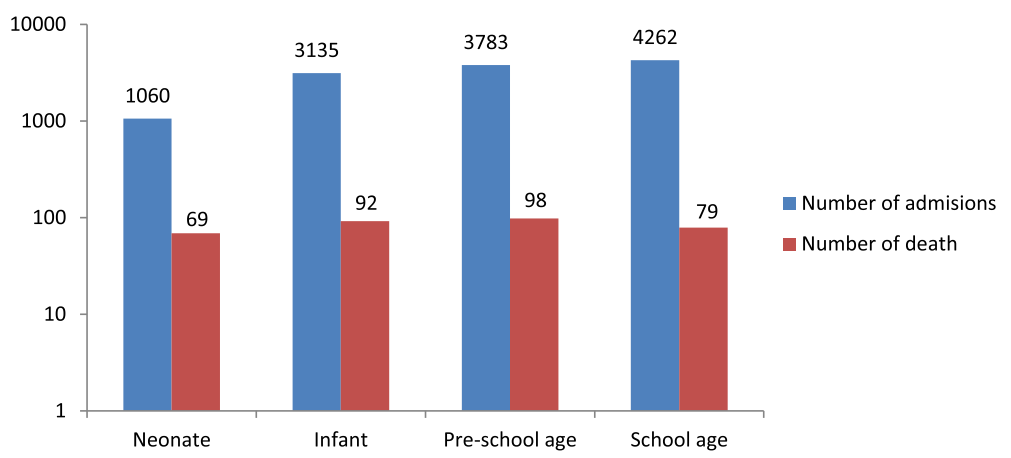

Fig. 2 Age categories with mortality rate and number of admissions in PED at TASTH, Addis Ababa from 2012 to 2016 inclusive

Approximately $32 \%$ of deaths were documented as early death (within $\leq 24 \mathrm{~h}$ of arrival in the pediatric emergency department). More than half (59\%) patients presented for treatment following at least two days of signs and/or symptoms (Table 1). In all the age groups, males were admitted more often than females (Fig. 1), with higher numbers of deaths occurring in the pre-school age and infant age group (Fig. 2). However, the highest mortality rate was seen in the neonatal age group (6\%), followed by infants $(2.9 \%)$, then the other age groups (Fig. 2).

The five most common presenting symptoms were fast breathing (66, 19.5\%), fever (48, 14.2\%), vomiting (41, $12.1 \%)$, cough $(38,11.2 \%)$, and shortness of breath (31, 9.2\%) (Fig. 3).

\section{Primary and secondary causes of death}

The primary causes of death $(n=298)$ were medical emergency diseases: these were cardiovascular diseases 83 (27.8\%), respiratory diseases 78 (26.2\%), infectious diseases 76 (25.5\%) and hematological diseases 32 (10.7\%).Surgical and accidental cases were contributed $7.4 \%$ and $4.4 \%$ for pediatric morality respectively (Table 2).

Two third of abdominal masses were malignancy-related masses; half of these were Wilm's tumors. Other presentations included renal failure (acute and/or chronic); severe traumatic brain injury (TBI) (epidural and/or subdural hematoma), increased intra-cranial pressure (ICP), and abdominal herniae after previous abdominal surgery.

Overall almost half of the primary causes of death had co-morbidities with secondary causes of mortality (including malnutrition, congenital heart defect, Down syndrome, malignant tumors, and low birth weight). Malnutrition and congestive heart disease were the most common co-morbidities associated with the primary causes of death. Prematurity (3.4\%), HIV/AIDS (2.7\%) and diabetes mellitus (1.4\%) were other less common co-morbidities (Table 2).

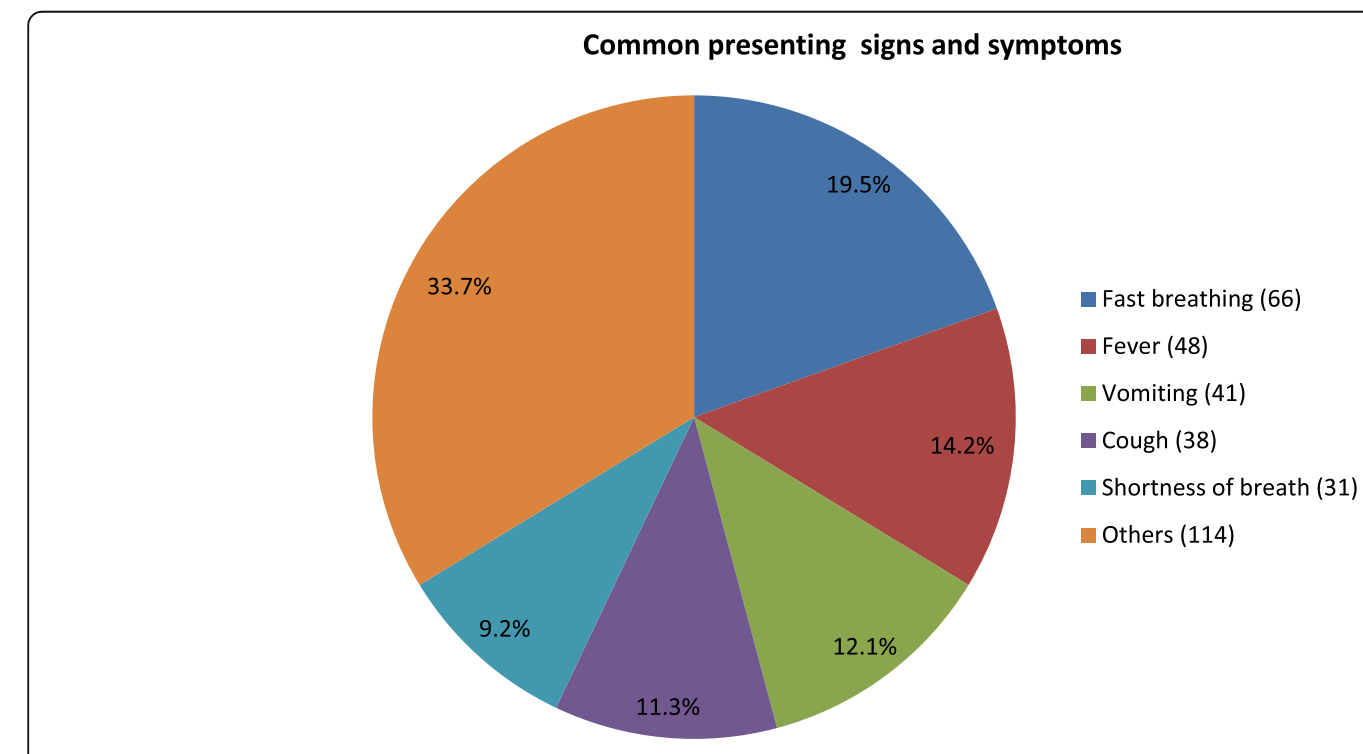

Fig. 3 Clinical common presenting symptoms of study participants in PED at TASTH, Addis Ababa from 2012 to 2016 inclusive 
Table 2 Frequency distribution of primary and secondary causes of death in PED at TASTH, Addis Ababa, from 2012 to 2016 inclusive

\begin{tabular}{|c|c|c|}
\hline Variables & Frequency & Percentage (\%) \\
\hline \multicolumn{3}{|c|}{ Medical emergency diseases $(N=298(88.25 \%))$} \\
\hline \multicolumn{3}{|l|}{ Respiratory diseases $(n=78)$} \\
\hline Severe pneumonia & 60 & 76.9 \\
\hline Tuberculosis & 13 & 16.7 \\
\hline Others & 5 & 6.4 \\
\hline \multicolumn{3}{|l|}{ Infectious diseases $(n=76)$} \\
\hline Sepsis & 40 & 52.6 \\
\hline Meningitis & 34 & 44.7 \\
\hline Malaria & 2 & 2.7 \\
\hline \multicolumn{3}{|l|}{ Cardiovascular diseases $(n=83)$} \\
\hline Congestive heart failure & 46 & 55.5 \\
\hline Hypovolemic shock & 20 & 24.1 \\
\hline Septic shock & 6 & 7.2 \\
\hline Pulmonary hypertension & 6 & 7.2 \\
\hline Cardiogenic shock & 3 & 3.6 \\
\hline Anaphylactic shock & 2 & 2.4 \\
\hline \multicolumn{3}{|l|}{ Hematological diseases $(n=32)$} \\
\hline Hematological malignancy & 15 & 46.9 \\
\hline Severe anemia & 14 & 43.8 \\
\hline Hemophilia & 3 & 9.3 \\
\hline \multicolumn{3}{|l|}{ Digestive diseases $(n=12)$} \\
\hline Diarrheal diseases & 7 & 58.3 \\
\hline Hepatic encephalopathy & 5 & 41.7 \\
\hline \multicolumn{3}{|l|}{ Renal diseases $(n=9)$} \\
\hline Renal failure (acute and chronic) & 8 & 88.9 \\
\hline Nephrotic syndrome & 1 & 11.1 \\
\hline \multicolumn{3}{|l|}{ Neurological diseases $(n=8)$} \\
\hline Seizure disorder & 5 & 62.5 \\
\hline Guillain-Barré syndrome & 2 & 25.0 \\
\hline Intra cranial pressure & 1 & 12.5 \\
\hline \multicolumn{3}{|l|}{ Surgical cases $(n=25)$} \\
\hline Abdominal mass & 9 & 36.0 \\
\hline Small bowel obstruction & 6 & 24.0 \\
\hline Large bowel obstruction & 4 & 16.0 \\
\hline Intussusception & 3 & 12.0 \\
\hline Others & 3 & 12.0 \\
\hline \multicolumn{3}{|l|}{ Accidental/unintentional injuries $(N=15)$} \\
\hline Severe traumatic brain injury & 5 & 33.3 \\
\hline Other than head injury & 8 & 53.4 \\
\hline Burn & 2 & 13.3 \\
\hline
\end{tabular}

Table 2 Frequency distribution of primary and secondary causes of death in PED at TASTH, Addis Ababa, from 2012 to 2016 inclusive (Continued)

\begin{tabular}{lll}
\hline Variables & Frequency & Percentage (\%) \\
\hline Secondary causes of death $(n=146)$ & & \\
Malnutrition & 60 & 41.1 \\
Congenital heart defect & 37 & 25.4 \\
Down syndrome & 21 & 14.4 \\
Malignant tumors & 10 & 6.8 \\
Low birth weight & 7 & 4.8 \\
Others & 11 & 7.5 \\
\hline
\end{tabular}

Note: Others: -For surgical cases (hydrocephalus, abdominal herniae), for respiratory diseases (ARDS, asthma), for secondary cause (prematurity, HIV, diabetes mellitus)

The top ten cause of mortality were pneumonia $17.8 \%$, congestive heart failure $13.6 \%$, sepsis $11.8 \%$, meningitis $10.1 \%$, hypovolemic shock $6 \%$, hematological malignancy $4.4 \%$, anemia $4.1 \%$, tuberculosis $3.9 \%$, abdominal mass $2.7 \%$ and renal failure $2.4 \%$ (Table 3 ).

The top causes for neonatal deaths were late-onset sepsis $(50.9 \%)$ and meningitis (24.6\%), while in infants, pneumonia (35.6\%) and congestive heart failure (23.3\%) were the main causes of death. This was similar in the preschool age children with pneumonia at $26.7 \%$ and congestive heart failure at $16 \%$. On the other hand, congestive heart failure was the most common cause of death for the school age group, followed by pneumonia and hematological malignancy. There were no neonatal cases of tuberculosis, renal failure, abdominal mass and hematological malignancy (Table 3).

Notably, malnutrition was a significant co-morbidity with all top ten causes of death in pediatric emergency. A congenital heart defect commonly contributed to death from congestive heart failure and pneumonia. HIV/AIDS was co-morbidity with tuberculosis and pneumonia while low birth weights were related with the late onset of sepsis and meningitis (Table 4).

Table 5 documents the result of crude and adjusted odds ratios after logistic regression. In univariate logistic regression analysis only six variables fulfilled the criteria of $p$-values less than 0.2 . These were age, duration of signs and symptoms, sign and symptoms, hematological malignancy, diarrheal disease and malnutrition.

In the multivariate logistic regression, shortness of breath, fast breathing, fever, late onset of signs and symptoms ( $>$ two days), and diarrheal disease were significantly associated with early rather than late pediatric mortality.

Children with shortness of breath were more likely to have an early death after emergency department admission than those developing other signs and symptoms $[\mathrm{AOR}=2.45,95 \%$ CI (1.22-4.91)]. Those participants presenting to an emergency unit after two days of illness 
Table 3 Distribution of age category groups with top ten causes of mortality in PED at TASTH, Addis Ababa, from 2012 to 2016 inclusive

\begin{tabular}{|c|c|c|c|c|}
\hline \multirow[t]{2}{*}{ Top ten causes of death } & \multicolumn{4}{|l|}{ Age category } \\
\hline & Neonate n (\%) & Infant n (\%) & Preschool age $n(\%)$ & School age $n(\%)$ \\
\hline Pneumonia $(n=60)$ & $6(10.5)$ & $26(35.6)$ & $20(26.7)$ & $8(14.8)$ \\
\hline Congestive heart failure $(n=46)$ & $4(7.0)$ & $17(23.3)$ & $12(16.0)$ & $13(24.1)$ \\
\hline Sepsis $(n=40)$ & $29(50.9)$ & $3(4.1)$ & $7(9.3)$ & $1(1.9)$ \\
\hline Meningitis $(n=34)$ & $14(24.6)$ & $13(17.8)$ & $5(6.7)$ & $2(3.7)$ \\
\hline Hypovolemic shock $(n=20)$ & $3(5.3)$ & $5(6.8)$ & $6(8.0)$ & $6(11.1)$ \\
\hline Hematological malignancy $(n=15)$ & - & - & $8(10.7)$ & $7(13.0)$ \\
\hline Anemia $(n=14)$ & $1(1.8)$ & $5(6.8)$ & $1(1.3)$ & $7(13.0)$ \\
\hline Tuberculosis $(n=13)$ & - & - & $6(8.0)$ & $7(13.0)$ \\
\hline Abdominal mass $(n=9)$ & - & $1(1.4)$ & $7(9.3)$ & $1(1.9)$ \\
\hline Renal failure $(n=8)$ & - & $3(4.1)$ & $3(4.0)$ & $2(3.7)$ \\
\hline
\end{tabular}

had three times greater odds of early mortality compared to those who presented earlier[AOR $=3.22,95 \%$ CI (1.34-7.73)]. Diarrheal disease and fever were also a risk factor for early child mortality (Table 5).

\section{Discussion}

Children presenting to our emergency department, had a mortality rate of $4.1 \%$. The incidence of pediatric mortality in this study was lower than the previous studies conducted in Ethiopia [23-26]. This decrease may be due to improvements in the maternal and child urban health care settings. Despite this low mortality rate, early death less than $24 \mathrm{~h}$ after admission 107 (31.7\%) was still high albeit, lower than other studies [18, 19, 26, 27].

The majority of pediatric emergency mortality in hospitals was due to preventable diseases within $24 \mathrm{~h}$ of admission [12]. This may be due to poor health care seeking behavior, delay in referral, using traditional medicine, and poverty [28]. A study done in Sub-Saharan countries on care-seeking behaviors related to respiratory illness were found that only $30 \%$ of Ethiopian children with suspected pneumonia were taken to a health care settings; this was the lowest proportion in the six analyzed countries [29]. Another study identified multiple factors influencing care-seeking behaviors in Ethiopian children including lack of knowledge, delay in recognition of illness severity and household income [30]. The main causes of neonatal death were late-onset sepsis (50.9\%), meningitis (24.6\%), and pneumonia (10.5\%). Previous studies done in Nigeria and Benin identified high rates of sepsis in this age group [20, 21, 31 , which may be due to unclean cord care practices, traditional birth attendant, polluted atmosphere and poor health education among parents [32].

Table 4 Top ten and co-morbidity cases of death in PED at TASTH, Addis Ababa, from 2012 to 2016 inclusive

\begin{tabular}{|c|c|c|c|c|c|c|c|c|}
\hline \multirow[t]{2}{*}{ Top ten diseases } & \multicolumn{8}{|c|}{ Secondary causes of mortality $(\mathrm{N}(\%))$} \\
\hline & Malnutrition & $\begin{array}{l}\text { Congenital } \\
\text { heart defect }\end{array}$ & Down syndrome & Malignancy tumor & Low birth weight & Prematurity & HIV & $\begin{array}{l}\text { Diabetes } \\
\text { mellitus }\end{array}$ \\
\hline Pneumonia $(n=30)$ & $17(56.7)$ & $7(23.3)$ & $2(6.7)$ & $1(3.3)$ & & $1(3.3)$ & $2(6.7)$ & \\
\hline $\begin{array}{l}\text { Congestive heart failure } \\
(n=43)\end{array}$ & $9(20.9)$ & $21(48.8)$ & $10(23.3)$ & $2(4.6)$ & & & $1(2.4)$ & \\
\hline Sepsis $(n=11)$ & $4(36.4)$ & $4(36.3)$ & $1(9.1)$ & & & $1(9.1)$ & & $1(9.1)$ \\
\hline Meningitis $(n=8)$ & $1(12.5)$ & & $3(37.5)$ & & $2(25)$ & $2(25)$ & & \\
\hline Hypovolemic shock $(n=8)$ & $3(37.5)$ & $2(25)$ & $3(37.5)$ & & & & & \\
\hline $\begin{array}{l}\text { Hematological malignancy } \\
(n=11)\end{array}$ & $7(63.6)$ & & & $4(36.4)$ & & & & \\
\hline Anemia $(n=4)$ & $3(75.0)$ & & & & $1(25.0)$ & & & \\
\hline Tuberculosis $(n=5)$ & $4(80.0)$ & & & & & & $1(20.0)$ & \\
\hline Abdominal mass $(n=1)$ & & & & $1(100)$ & & & & \\
\hline Renal failure $(n=1)$ & $1(100)$ & & & & & & & \\
\hline
\end{tabular}


Table 5 Factors (crude and adjusted odds ratios and confidence intervals) associated with early pediatric mortality in PED at TASTH, Addis Ababa from 2012 to 2016 inclusive

\begin{tabular}{|c|c|c|c|c|c|}
\hline \multirow[t]{2}{*}{ Variables } & \multicolumn{2}{|c|}{ Mortality } & \multirow[t]{2}{*}{$\operatorname{COR}(\mathrm{Cl}, 95 \%)$} & \multirow[t]{2}{*}{$\mathrm{AOR}(\mathrm{Cl}, 95 \%)$} & \multirow{2}{*}{$\begin{array}{l}p \\
\text { value }\end{array}$} \\
\hline & $\leq 24 \mathrm{~h}$ & $>24 \mathrm{~h}$ & & & \\
\hline \multicolumn{6}{|l|}{$\overline{\text { Age }}$} \\
\hline Neonate & 24 & 45 & $1.47(0.73-2.98)$ & $0.96(0.44-2.09)$ & 0.982 \\
\hline Infant & 31 & 61 & $1.40(0.73-2.72)$ & $1.15(0.56-2.36)$ & 0.912 \\
\hline Preschool age & 34 & 64 & $1.47(0.77-2.81)$ & $1.57(0.77-3.21)$ & 0.187 \\
\hline School age & 21 & 58 & 1.00 & 1.00 & \\
\hline \multicolumn{6}{|c|}{ Duration of signs and symptoms } \\
\hline$\leq$ two days & 57 & 77 & 1.00 & 1.00 & \\
\hline$>$ two days & 53 & 151 & $2.11(1.33-3.35)$ & $3.22(1.34-7.73)^{* *}$ & 0.004 \\
\hline \multicolumn{6}{|l|}{ Sign and symptoms } \\
\hline Fast breathing & 18 & 28 & $2.21(1.00-4.88)$ & $2.78(1.19-6.49)^{*}$ & 0.020 \\
\hline Fever & 15 & 20 & $2.58(1.10-6.05$ & $3.17(1.28-7.86)^{*}$ & 0.019 \\
\hline Vomiting & 9 & 23 & $1.35(0.53-3.42)$ & $1.48(0.55-4.03)$ & 0.573 \\
\hline Cough & 5 & 29 & $0.59(0.20-1.76)$ & $0.70(0.23-2.18)$ & 0.625 \\
\hline Shortness of breath & 45 & 66 & $2.35(1.23-4.49)$ & $2.45(1.22-4.91)^{* *}$ & 0.006 \\
\hline Other diseases & 18 & 62 & 1.00 & 1.00 & \\
\hline \multicolumn{6}{|c|}{ Hematological malignancy } \\
\hline Yes & 4 & 11 & $0.74(0.23-2.39)$ & $1.08(0.29-4.03)$ & 0.814 \\
\hline No & 106 & 217 & 1.00 & 1.00 & \\
\hline \multicolumn{6}{|l|}{ Diarrheal disease } \\
\hline Yes & 85 & 208 & $3.06(1.61-5.80)$ & $3.36(1.69-6.67)^{* *}$ & 0.009 \\
\hline No & 25 & 20 & 1.00 & 1.00 & \\
\hline \multicolumn{6}{|l|}{ Malnutrition } \\
\hline Yes & 24 & 67 & $1.49(0.87-2.55)$ & $1.43(0.79-2.57)$ & 0.226 \\
\hline No & 86 & 161 & 1.00 & 1.00 & \\
\hline
\end{tabular}

Other signs and symptoms included respiratory distress, swelling, coma, convulsion, grunting, abdominal pain, distension, headache, failure to suck Note: ${ }^{*}$ Significant association ( $p$-value $<0.05$ ), ${ }^{* *}$ significant association ( $p$-value $<0.01$ ), Hosmer and Lemeshow goodness of fit test $=0.985$ COR crude odds ratio, $A O R$ adjusted odds ratio

We found that the primary causes of death for the infant and pre-school age groups at TASTH were pneumonia, congestive heart failure, meningitis, and sepsis and hypovolemic shock. This is similar to previous work in China, Nigeria, Ghana, India and a World Health Organization (WHO) report $[19,20,22,33,34]$. In Ethiopia, pneumonia is an important public health problem for all children, and creates a significant burden of childhood mortality $[18,35]$. A health extension program package focused on disease prevention and health education targeting antibiotic treatment for childhood pneumonia might be a solution to decrease deaths from pneumonia. However, there are some challenges in promoting a health extension program package due to knowledge gaps of health extension workers such as misdiagnosis, negligence and inappropriate referrals [36, 37]. These problems need to be addressed and improved because pneumonia contributes to the high early pediatric mortality in developing countries [38].

Our study found that congestive heart failure and hematological malignancy were top primary causes of school age group mortality. This is consistent with findings in China and Nigeria [19-21], but quite different to other studies in Nigeria, Ethiopia and sub-Saharan Africa countries which suggested a smaller role for these conditions $[26,39$, 40]. This disparity may be due to lack of cardiac and pediatric oncology services in developing countries. Many low- and middle-income countries lack pediatric cardiac care programs, resulting insignificant mortality from congenital heart diseases [41]. Other possible causes include lack of primary care, screening and health follow-up in low income countries. However, even with early diagnosis, accesses to expensive chemotherapy agents and/or specialized cardiac surgery are also severely limited. 
Our study found that the most five common presenting symptoms of children who died within the PED were shortness of breath, fast breathing, fever, vomiting, and cough. Shortness of breath, fever and fast breathing were associated with early mortality when compared to the other common presenting symptom. These findings are similar to the studies found in Ghana and South East Nigeria [22, 42].

These common signs and symptoms are usually identified by emergent assessment of airway, breathing and circulation [13, 14, 43]. Consequently, immediate treatment and management is critical, particularly for airway obstruction that leads to severe illness and death when left untreated. Early triage assessment and identification of signs of critical illness, and rapid initiation of appropriate treatment should be priorities for all hospitals providing emergency care for children.

Malnutrition and diarrhea were common co-morbid conditions associated with the primary causes of death. This is consistent with studies conducted in Kenya, Ghana [22, 44] and Ethiopia [18, 26]. Additionally, in our study diarrheal disease was significantly associated with pediatric mortality. In Africa, many studies have identified diarrheal disease to be a significant cause of death in childhood [20, 22, 25, 44-51].

Malnutrition was a co-morbid condition in one-third of pediatric deaths. Micronutrient initiative programs and multi-sector collaboration may be useful interventions to improve community awareness of the importance of balanced nutrition. However, difficulty accessing or affording food is a significant challenge for large numbers of African children [52].

Our study has potential limitations. This includes the retrospective study design, and the reliance on interpretation of documentation within the medical record. In some cases, it was difficult to obtain adequate study information. Unfortunately, we were unable to collect data on almost one-third of all cases due to incomplete documentation $(95,19.1 \%)$ of the patient's medical history, loss of the medical chart $(66,13.2 \%)$ and one patient who had multiple diagnoses recorded, rendering it difficult to identify primary and secondary causes of mortality.

\section{Conclusion}

The total mortality rate of children in this study was $4.1 \%$ with a high proportion $(31.7 \%)$ of early mortality. Pneumonia, congestive heart failure, sepsis, meningitis, late-onset sepsis and hematological diseases were the most common causes of death in children presenting to our emergency department. A delay in presentation of more than $48 \mathrm{~h}$, diarrheal diseases and shortness of breath were significantly associated with early pediatric mortality. Almost all mortality was due to preventable diseases, which can be controlled with minimum resources and quality care provision. We were unable to extract data for a significant proportion of patients due to limitations of and/or missing medical documentation. Efficient, evidence-based triage and intervention by trained ED staff may improve child mortality. Further longitudinal studies on pediatric emergency patients in the African setting are warranted.

\section{Abbreviations \\ AIDS: Acquired immune deficiency syndrome; ARDS: Acute respiratory disease syndrome; CHF: Congestive heart failure; ED: emergency department; GBS: Guillain-Barré syndrome; HIV: Human immunodeficiency virus; HTN: Hypertension; LBW: Low birth weight; PED: Pediatric emergency department; SOB: Shortness of breath; TASTH: Tikur Anbessa Specialized Tertiary Hospital; WHO: World Health Organization}

\section{Acknowledgements}

The authors acknowledge TASTH for funding this study, and emergency departments and HMIS department for their cooperation. Our great gratitude goes to pediatrician Professor Khalid Aziz, Department of pediatrics University of Alberta, Canada for his proofreading and kind support.

\section{Funding}

This research work is funded by Addis Ababa University.

\section{Availability of data and materials}

The datasets used and/or analyzed during the current study are available from the corresponding author on reasonable request.

\section{Authors' contributions \\ GJ, TB, LB and $\mathrm{KJ}$ are conceived the study and was involved in the study design, reviewed the article, analysis, report writing and drafted the manuscript. They have reviewed and approved the submission of the manuscript.}

\section{Ethics approval and consent to participate}

Ethical clearance and approval were obtained from the Ethical Committee of the Department of Emergency Medicine, College of Health Science, School of Medicine, Addis-Ababa University. Official letter was obtained from the Department of Emergency Medicine to the clinical director of TASTH. The ethical approval was received from the ethical committee for verbal consent from pediatric emergency department and Card Room staff before joining the study. Confidentiality was maintained in each level of the response. In view of the retrospective nature of this study and the secondary use of data from the health management information system database, study participant and family member consent was waived.

\section{Consent for publication \\ Not applicable.}

\section{Competing interests}

The authors declare that they have no competing interests.

\section{Publisher's Note}

Springer Nature remains neutral with regard to jurisdictional claims in published maps and institutional affiliations.

\section{Author details}

${ }^{1}$ Addis Ababa Regional Health Bureau Department of Emergency, Box 245, Addis Ababa, PO, Ethiopia. ${ }^{2}$ Department of Nursing, Salale University College of Health Sciences, Fitche, Ethiopia. ${ }^{3}$ Department of Emergency Medicine, Addis Ababa University College of Health Sciences, School of Medicine, Addis Ababa, Ethiopia. ${ }^{4}$ Department of Pediatric and Child Health, Division of Emergency Medicine and Critical Care, Addis Ababa University College of Health Sciences, School of Medicine, Addis Ababa, Ethiopia. 


\section{Received: 18 December 2017 Accepted: 17 September 2018} Published online: 02 October 2018

\section{References}

1. Liu L, Oza S, Hogan D, Perin J, Rudan I, Lawn JE, et al. Global, regional, and national causes of child mortality in 2000-13, with projections to inform post-2015 priorities: an updated systematic analysis. Lancet. 2015;385(9966): 430-40.

2. Rajaratnam JK, Marcus JR, Flaxman AD, Wang H, Levin-Rector A, Dwyer L, et al. Neonatal, postneonatal, childhood, and under-5 mortality for 187 countries, 1970-2010: a systematic analysis of progress towards millennium development goal 4. Lancet. 2010;375(9730):1988-2008.

3. Organization WH. World health statistics 2010: World Health Organization; 2010.

4. Harper SA, Bradley JS, Englund JA, File TM, Gravenstein S, Hayden FG, et al Seasonal influenza in adults and children-diagnosis, treatment, chemoprophylaxis, and institutional outbreak management: clinical practice guidelines of the Infectious Diseases Society of America. Clin Infect Dis. 2009:1003-32

5. Morris SS, Black RE, Tomaskovic L. Predicting the distribution of under-five deaths by cause in countries without adequate vital registration systems. Int J Epidemiol. 2003;32(6):1041-51.

6. Hochstadt NJ. Child death review teams: a vital component of child protection. Child Welfare. 2006;85(4):653

7. Campbell H, Duke T, Weber M, English M, Carai S, Tamburlini G. Globa initiatives for improving hospital care for children: state of the art and future prospects. Pediatrics. 2008;121(4):e984-e92.

8. Duke T, Kelly J, Weber M, English M, Campbell H. Hospital care for children in developing countries: clinical guidelines and the need for evidence. Oxford University Press. 2006

9. Michalski T. The differentiation of the health situation in European postcommunist countries after 1990. Geography and Tourism. 2016;4(1):33-42.

10. Duke T. New WHO guidelines on emergency triage assessment and treatment. Lancet. 2016;387(10020):721-4.

11. Fajolu I, Egri-Okwaji M. Childhood mortality in children emergency Centre of the Lagos University teaching hospital. Nigerian Journal of Paediatrics. 2011;38(3):131-5

12. Moss WJ, Ramakrishnan M, Storms D, Henderson Siegle A, Weiss WM, Lejnev I, et al. Child health in complex emergencies. Bull World Health Organ. 2006;84:58-64.

13. Molyneux E, Ahmad S, Robertson A. Improved triage and emergency care for children reduces inpatient mortality in a resource-constrained setting. Bull World Health Organ. 2006;84:314-9.

14. Li MY, Kelly J, Subhi R, Were W, Duke T. Global use of the WHO pocket book of hospital care for children. Paediatrics and International Child health. 2013;33(1):4-11

15. Okechukwu A, Nwalozie C. Morbidity and mortality pattern of admissions into the emergency Paediatric unit of University of Abuja Teaching Hospital, Gwagwalada. Nigerian Journal of Medicine: Journal of the National Association of Resident Doctors of Nigeria. 2011;20(1):109-13.

16. Abebe T, Girmay M. The epidemiological profile of pediatric patients admitted to the general intensive care unit in an ethiopian university hospital. International Journal of General medicine. 2015;8:63.

17. Robison JA, Ahmad ZP, Nosek CA, Durand C, Namathanga A, Milazi R, et al. Decreased pediatric hospital mortality after an intervention to improve emergency care in Lilongwe, Malawi. Pediatrics. 2012;130(3):e676-e82.

18. Gordon DM, Frenning S, Draper HR, Kokeb M. Prevalence and burden of diseases presenting to a general pediatrics ward in Gondar, Ethiopia. J Trop Pediatr. 2013;59(5):350-7.

19. C-p Z, Wu X-h, Y-t L, Ma W-c, Ren L. The mortality of patients in a pediatric emergency department at a tertiary medical center in China: an observational study. World J Emerg Med. 2015;6(3):212.

20. Anyanwu OU, Ezeanosike OB, Ezeonu CT. Pattern and outcome of admissions at the children emergency room at the Federal Teaching Hospital Abakaliki. African Journal of Medical and Health Sciences. 2014;13(1):6.

21. Forae GD, Uchendu OJ, Igbe AP. An audit of paediatric mortality patterns in a Nigerian teaching hospital. Nigerian Medical Journal: Journal of the Nigeria Medical Association. 2014,55(2):130.

22. Tette EM, Nyarko MY, Nartey ET, Neizer ML, Egbefome A, Akosa F, et al. Under-five mortality pattern and associated risk factors: a case-control study at the Princess Marie Louise Children's Hospital in Accra, Ghana. BMC Pediatr. 2016;16(1):148
23. Susuman AS. Child mortality rate in Ethiopia. Iran J Public Health. 2012;41(3):9

24. Mekonnen Y, Tensou B, Telake DS, Degefie T, Bekele A. Neonatal mortality in Ethiopia: trends and determinants. BMC Public Health. 2013;13(1):483.

25. Murray CJ, Laakso T, Shibuya K, Hill K, Lopez AD. Can we achieve millennium development goal 4? New analysis of country trends and forecasts of under-5 mortality to 2015. Lancet. 2007;370(9592):1040-54.

26. Bohn J, Kassaye B, Record D, Chou B, Kraft I, Purdy J, et al. Demographic and mortality analysis of hospitalized children at a referral hospital in Addis Ababa, Ethiopia. BMC Pediatr. 2016;16(1):168

27. Ndukwu C, Onah S. Pattern and outcome of postneonatal pediatric emergencies in Nnamdi Azikiwe University teaching hospital, Nnewi, south East Nigeria. Niger J Clin Pract. 2015;18(3):348-53.

28. Okposio MM, Unior MO, Ukpeteru FO. Sociodemographic determinants of mortality in hospitalized under-five children at a secondary health Care Centre in the Niger Delta. 2012.

29. Noordam AC, Carvajal-Velez L, Sharkey AB, Young M, Cals JW. Correction: care seeking behaviour for children with suspected pneumonia in countries in sub-Saharan Africa with high pneumonia mortality. PLoS One. 2015;10(4): e0126997.

30. Awoke W. Prevalence of childhood illness and mothers'/caregivers' care seeking behavior in Bahir Dar, Ethiopia: a descriptive community based cross sectional study. Open Journal of Preventive Medicine. 2013;3(02):155.

31. Abhulimhen-Iyoha B, Okolo A. Morbidity and mortality of childhood illnesses at the emergency paediatric unit of the University of Benin Teaching Hospital, Benin City. Nigerian Journal of Paediatrics. 2012;39(2):71-4.

32. Ayoola O, Orimadegun A, Akinsola A, Osinusi K. A five-year review of childhood mortality at the university college hospital, Ibadan. West Afr J Med. 2005;24(2):175-9.

33. Mahajan V, Kaur A, Sharma A, Azad C, Guglani V. Modifiable factors for prevention of childhood mortality. Indian Pediatr. 2014;51(1):45-7.

34. Organization $\mathrm{WH}$. Protecting health from climate change: connecting science, policy and people. 2009.

35. Walker CLF, Rudan I, Liu L, Nair H, Theodoratou E, Bhutta ZA, et al. Global burden of childhood pneumonia and diarrhoea. Lancet. 2013;381(9875): 1405-16.

36. Getnet FHA, Mohamud S, Mowlid H, Klinkenberg E. Low contribution of health extension workers in identification of persons with presumptive pulmonary tuberculosis in Ethiopian Somali region pastoralists. BMC Health Serv Res. 2017;2017(1):193.

37. Kok MCKA, Datiko DG, Broerse JE, Dieleman M, Taegtmeyer M, Tulloch O. A qualitative assessment of health extension workers' relationships with the community and health sector in Ethiopia: opportunities for enhancing maternal health performance. Hum Resour Health. 2015;13(1):80

38. Miller NP, Amouzou A, Tafesse M, Hazel E, Legesse H, Degefie T, et al. Integrated community case management of childhood illness in Ethiopia: implementation strength and quality of care. The American Journal of Tropical Medicine and Hygiene. 2014;91(2):424-34.

39. Nte A, Ekanem E, Gbaraba P, Oruamabo R. Social-environmental influences on the occurrence of neonatal tetanus in some riverine communities in Nigeria. Trop Dr. 1997;27(4):234

40. Noordam AC, Carvajal-Velez L, Sharkey AB, Young M, Cals JW. Care seeking behaviour for children with suspected pneumonia in countries in subSaharan Africa with high pneumonia mortality. PLoS One. 2015;10(2): e0117919.

41. Beaglehole R, Bonita R, Horton R, Adams C, Alleyne G, Asaria P, et al. Priority actions for the non-communicable disease crisis. Lancet. 2011;377(9775):1438-47.

42. Iloh GU, Ofoedu JN, Njoku PU, Amadi AN, Godswill-Uko EU. The magnitude of under-five emergencies in a resource-poor environment of a rural Hospital in Eastern Nigeria: implication for strengthening the house-hold and Community-integrated Management of Childhood IIInesses. N Am J Med Sci. 2012:4(8):344

43. Organization WH. Serious childhood problems in countries with limited resources. 2004

44. Moïsi JC, Gatakaa H, Berkley JA, Maitland K, Mturi N, Newton CR, et al. Excess child mortality after discharge from hospital in Kilifi, Kenya: a retrospective cohort analysis. Bull World Health Organ. 2011;89(10):725-32.

45. Wardlaw T, Salama P, Brocklehurst C, Chopra M, Mason E. Diarrhoea: why children are still dying and what can be done. Lancet. 2010;375(9718):870-2.

46. Caulfield LE, de Onis M, Blössner M, Black RE. Undernutrition as an underlying cause of child deaths associated with diarrhea, pneumonia, malaria, and measles. Am J Clin Nutr. 2004;80(1):193-8. 
47. Gupta A, Sarker G, Rout AJ, Mondal T, Pal R. Risk correlates of diarrhea in children under 5 years of age in slums of Bankura, West Bengal. J Global Infect Dis. 2015;7(1):23.

48. Llale MA. How well do mothers and caregivers prepare oral rehydration solution 2017

49. Black RE, Cousens S, Johnson HL, Lawn JE, Rudan I, Bassani DG, et al. Global, regional, and national causes of child mortality in 2008: a systematic analysis. Lancet. 2010;375(9730):1969-87.

50. Bryce J, Boschi-Pinto C, Shibuya K, Black RE, Group WCHER. WHO estimates of the causes of death in children. Lancet. 2005;365(9465):1147-52.

51. O'Reilly CE, Jaron P, Ochieng B, Nyaguara A, Tate JE, Parsons MB, et al. Risk factors for death among children less than 5 years old hospitalized with diarrhea in rural western Kenya, 2005-2007: a cohort study. PLoS Med. 2012; 9(7):e1001256.

52. Approach to Nutrition Programming in the East Asia and Pacifc Region, 2014 - 2025. UNICEF. 2014.

Ready to submit your research? Choose BMC and benefit from:

- fast, convenient online submission

- thorough peer review by experienced researchers in your field

- rapid publication on acceptance

- support for research data, including large and complex data types

- gold Open Access which fosters wider collaboration and increased citations

- maximum visibility for your research: over $100 \mathrm{M}$ website views per year

At $\mathrm{BMC}$, research is always in progress.

Learn more biomedcentral.com/submissions 